\title{
Between Ambitions and Ambivalences: Cross-cultural Diversity Management and Immigrant Integration
}

\author{
Laura Zanfrini ${ }^{1}$, Massimiliano Monaci ${ }^{2}$ \\ ${ }^{1}$ Full Professor of Sociology of Migrations and Ethnic Relations, WWELL Research Center, Department of Sociology, \\ Università Cattolica del Sacro Cuore, Milan, Italy \\ ${ }^{2}$ Associate Professor of Organizational Sociology, WWELL Research Center, Department of Sociology, Università \\ Cattolica del Sacro Cuore, Milan, Italy
}

Correspondence: Massimiliano Monaci, Associate Professor of Organizational Sociology, WWELL Research Center, Department of Sociology, Università Cattolica del Sacro Cuore, Milan, Italy.

Received: December 14, 2016

doi:10.11114/bms.v3i1.2211
Accepted: January 31, 2017

Online Published: February 8, 2017

URL: http://dx.doi.org/10.11114/bms.v3i1.2211

Laura Zanfrini is the author of sections 1, 2 and 7; Massimiliano Monaci of sections 4, 5 and 6. Section 3 is to be attributed to both authors.

\begin{abstract}
This article provides an outline and discussion of the main findings of an international research realized in $10 \mathrm{EU}$ countries on Cross-cultural Diversity Management practices for immigrant workers. The fundamental aim is to explore the role of such practices for the promotion of a new model of integration based on the exploitation of immigrants' human capital as a strategic lever for EU competitiveness. This goal is achieved through a targeted selection and a re-elaboration of the key indications from the research, which entailed desk-based analyses and the carrying out of more than 100 case histories of for-profit, public and not-for-profit organizations. By focusing on the variety of the observed practices and their impact in the context of a broader reflection on immigrant integration in EU countries, the paper suggests that there is potential for the development of significant diversity management actions towards immigrant workers.
\end{abstract}

Keywords: cross-cultural diversity management, corporate social responsibility, human resource management, immigrant workers, immigrant integration, EU countries, migratory policies

\section{Introduction}

Contrasting with the ideology underpinning the process of nation-building in Europe, diversity within nowadays' European societies may be qualified as an unexpected and "unwelcome" phenomenon. Diversity can be understood as the upshot of migratory policies and practices which have structurally transformed the population of nation-States.

In line with the traditional definition of migrants as temporary workers expected to fill low-status jobs, the European approach to immigration continues to obey a logic of complementarity. On the one hand, this clashes with the principle of equal rights and opportunities; on the other hand, it prevents the full exploitation of migrants' potential. Starting therefrom, enhancing a Human Resource Management (HRM) approach aimed to acknowledge and exploit the diversity induced by migrations would be a strategic asset in order to positively shape common expectations about their role.

Drawing evidence from an international project conducted in $10 \mathrm{EU}$ countries, ${ }^{2}$ this article outlines the specific role of Diversity Management (DM) practices directed towards immigrant workers from Third Countries (Third Country

\footnotetext{
${ }^{1}$ According to this logic, migrant workers do not compete with natives since they are concentrated in different kinds of job, i.e. jobs that natives do not want to do any more.

2 The project DIVERSE was supported by the European Commission (Grant Agreement HOME/2012/EIFX/CA/CFP/4248*30-CE-0586564/00-20), directed by Laura Zanfrini, coordinated by the Research Center WWELL -Work, Welfare, Enterprise, Lifelong Learning- of the Università Cattolica del Sacro Cuore of Milan, and implemented in cooperation with 13 partners in $10 \mathrm{EU}$ countries.
} 
Nationals, TCNs) as well as the impact of such practices on the "reinvention" of an EU migration and integration model. Notwithstanding the scant attention devoted to the issue in the existent literature, our article suggests that the "machine" is on the move. As will filter through in the following sections, its contribution consists in: a) identifying a multiplicity of organizational processes oriented towards the integration of TCNs into workplaces, and to the exploitation of their human capital and distinctive abilities; b) grasping a number of positive impacts related to cross-cultural DM on both immigrant employees and organizations employing them; c) glimpsing at major critical points that must receive attention in order to analyze and promote initiatives in this field; d) linking the above-listed aspects to the peculiarity and ambivalences of the European legacy and current experience with respect to migration and diversity. The next two sections draw the state of affairs as regards Europe's traditional view of migrations, DM practices and the attention paid to it in the specialized literature. Noting the scant attention paid to DM thus far, we then propose a new lens through which to look at the phenomenon. Section four presents the method employed in this research, before turning to the empirical evidence in sections five and six. We conclude this paper with a discussion of our findings and impacts of DM practices on both migrants' integration and society as a whole.

\section{Unexpected and Unwelcome: A State of Affairs of Diversity in Europe}

By insisting on the ethnic, religious, cultural and linguistic homogeneity of the population constituting the nation-State, the process of nation-building in Europe has ended up neglecting the "diversity" dimension. Wars, ethnic cleansings, mass denaturalization and forced expulsions are the price European States paid to impose faith in a "natural" isomorphism among the territory, the sovereign, the State, the citizenry, and the relation of solidarity between citizens. It is therefore not surprising if a strong strategy of border policing -in order to limit, control and select migrants- went hand in hand with the process of nation-building (Wimmer and Glick Schiller, 2003). As outlined by the same authors, this process is not specific to European countries. Nevertheless, it assumes particular features in Europe; notably in West European countries, which were the first to import labor from abroad. More precisely, after the conclusion of the free movement era, at the outbreak of the First World War, such specificity consisted in linking 'the right to reside in a country with a work permit, virtually defining a foreigner as a temporary worker' (Wimmer and Glick Schiller, 2003: 590). As the present article shows, this "imperfect" solution may well be the source of the paradoxes and ambivalences European countries have been facing in their difficult relationship with migrants.

If one considers the ideology at the foundation of the nation-State, immigrants constitute a threat to the principle of isomorphism. They are perceived as: foreign to the community of shared loyalty to the State and shared rights guaranteed by the State; politically dangerous, and nationally or racially fundamentally different, they are the "others" (ibid.). Civic education, national military service and mass media are all instruments that established and fed the "fiction" of a unique and unified people. The latter was represented as sharing the same homeland, the same ancestry -if not the same "blood"- and the same destiny, an ensemble tied by a sense of mutual solidarity (that will later be institutionalized through the establishment of the different national variants of Welfare State). This necessarily goes with a clear separation between the community of nationals and the others, the former being "naturally" entitled with rights, protection, and opportunities reserved to the citizens; i.e. the "owners of the State".

Accordingly, migration has been largely regulated following a logic of temporariness and economic functionality, as happened during the two great wars, with the forced importation of migrants destined to replace the native workers sent to the frontline. Finally, immediately after the Second World War, the institutionalization of the temporary work model, decidedly typical of the European experience (Papademetriou and Hamilton, 1995), marked an "aversion" to the prospect of a stable settlement of immigrant families and communities. Through the rhetorical figure of the "guest worker", European societies legitimized the differential treatment reserved to the "others" -the non-nationals- and their "natural" concentration in the lowest layers of professional stratification, thus assuming a relation of complementarity between migrants and native workers. Typical of countries like Germany, Austria and Belgium -commonly regarded as exemplars of the differential exclusion model (Castles and Miller, 2012)-, temporary labor schemes were also embraced by nations with a colonial past (such as France) to regulate the entry of different categories of migrants. In the 1990s this approach was adopted by "new" migration countries in Southern Europe too, and, as will be seen, it continues to represent the foundation of policies for economic migrations throughout the EU (OECD and EU, 2016), including the States which recently joined the Union.

Indeed, once confronted with the human rights philosophy, deeply rooted in the European civilization, this approach has proven dysfunctional. In spite of that, contemporary migration policies continue to obey the same logic, displaying new versions of the old guest-worker model. Beyond national variations, new entries are usually regulated according to the contingent needs of the labor market, by issuing temporary permits, which, in a more or less patent manner, limit 
migrants' professional and geographical mobility, thus substantially reaffirming the complementarity paradigm. ${ }^{3}$ In so doing, migration policies constantly reproduce the "unresolved paradox of the European legacy" (Zanfrini, 2010); that is, the attempt to keep together two clashing philosophies: the "economistic" philosophy, on which the system of entry (and stay) is founded, and the philosophy of solidarity, human rights and equal opportunities. It is worth noting that this approach is also applied in non-democratic countries importing foreign workforce, for instance in South-East Asia (Jamal, 2015). However, in the European context, this inevitably collides with antidiscrimination principles and equality ambitions.

Immediately following the start of decolonization, migrants coming from colonial territories were attributed a special preferred- treatment, and often inserted straight away into the community of "full citizens" (Miège, 1993). Many guest-workers did not return to their home countries but became permanent residents (Castles, 1986): they were often granted the status of "denizen" (Hammar, 1989) and awarded the right to family reunion, thus giving rise to large migration movements (Valtolina, 2013; Zanfrini, 2012) of people not selected for their professional profile. Conflicts and humanitarian crises produced large influxes of asylum seekers, many of them were accorded permanent protection (Carrera et al., 2015). The emergence of new immigration countries in the Southern periphery of Europe (King et al., 2000) pulled hundreds of thousands of undocumented migrants, most of them later regularized and attributed the long-term resident status (Triandafyllidou and Vogel, 2010). The redefinition of national borders further to the implosion of the Soviet Union generated new minority groups within the territory of the single States (Okólski, 2012), and sometimes also new groups of "foreigners" who suddenly lost their status of citizen. Finally, the progressive enlargement of EU borders has constantly redefined that fundamental division line between EU and non-EU migrants.

Confronted with the need to manage the inclusion of millions of individuals not selected according to their ethnic and cultural characters (OECD, 2014) -or, in other words, not in line with the ideology of homogeneity which inspired the process of nation-building-European societies have been strongly challenged by the need to respect the basic principles of their civilization, further reinforced by the process of "Europeanization of citizenship" (Delanty, 2006) (see for example the Directives on antidiscrimination and minority protection); not to mention the initiative of various components of civil society, which lobby for the inclusion of migrants into the community of the "insiders". Finally, through the institutionalization of long-term or permanent residence permits ${ }^{5}$ and the adoption of legislation relating to the acquisition of citizenship, Europe has become an authentic "diverse" society.

\section{A New Lens through Which to Look at Diversity with the DIVERSE Project}

To some degree, Europe has not really chosen to become so diverse (and the same can be affirmed for many organizations, which have not really chosen to become so heterogeneous in their staff composition). This is substantially an unplanned outcome, partly due to a gap between official migration policies and the effective evolution of migratory phenomena (Castles and Miller, 2012). The upshot of these forces has inspired thousands of essays and continues to feed the political debate in all European countries. The present discussion will not dwell on these arguments or elaborate on whether diversity is a bad or good thing. Rather, we acknowledge the by now structural -and incorrigible- heterogeneous composition of the European population and look at the real challenge ahead: how to manage it, and how to transform it into a competitive asset.

The long-established approach based on a complementarity philosophy has produced the segregation of migrants in low qualified and low status jobs, and their overrepresentation among precarious and unemployed workers. It has thus reinforced the segmentation of the labor market and its discriminatory nature according to the workers' ascribed status (OECD, 2015). As a matter of fact, migrants are frequently overqualified (i.e. they often have a higher education level

\footnotetext{
${ }^{3}$ This is confirmed by both the research commented here and a recent OECD report (2016).
}

${ }^{4}$ This definition applies to people who, although not having acquired the citizenship of the host country, are treated in an almost equal manner with nationals in the access to citizenship rights (the main exception is generally represented by their exclusion from political rights). More than 12 million TCNs living in the EU have obtained this condition.

${ }^{5}$ The European Union grants European long-term resident status to non-EU nationals who have legally and continuously resided for a period of five years within the territory of an EU country (Council Directive 2003/109/EC of $25^{\text {th }}$ November 2003).

${ }^{6}$ In line with the suggestions coming from the main international experts, many EU countries have changed their legislations reinforcing the jus soli principle; among these, Belgium, France, Germany, Ireland, Luxembourg and Portugal. In other countries (e.g. Italy), this issue is under discussion. 
than that required for the job) and are discouraged from applying for recognition of their credentials (Huddlestone and Dag Tjaden, 2012). They even happen to internalize their role of "temporary worker" in spite of their long-term stay in the country, and segregate themselves in ethnic niches, renouncing to fully participate in the social and cultural life. Such situation most likely has consequences for interethnic relations and social cohesion. Accordingly, managing diversity is by no means a merely ethical question, it is first and foremost a fundamental issue for the long-term development of a knowledge-based and innovative economy, as Europe claims to be. The issue becomes even more salient if one considers the demographic weight of people with a migratory background within the present and the future European landscape: how to fully benefit from migrants' (and their offspring's) contribution for the construction of a competitive economy has become a crucial issue (Alba and Foner, 2015; Crul and Mollenkof, 2012).

This is exactly the challenge at the core of the project DIVERSE, Diversity Improvement as a Viable Enrichment Resource for Society and Economy, whose findings are presented in this article. The project's fundamental aim was to shift from the perception of migrants as a contingently instrumental workforce supply to the conception of their human capital as a structural resource for the economic and social development of European societies. Raising awareness about the potential of DM practices among different types of organizations and through the involvement of various categories of stakeholders was identified as a key lever for intervention ${ }^{7}$ in this domain. The ultimate goal was the generation of a shared value -a "Diversity Value" (Zanfrini, 2015)- that promotes the realization of migrants' potential. In fact, in order to achieve this ambition, a fundamental step is to fill knowledge gaps about the opportunity of both recognizing and valorizing the distinctive experience and skills of workers with a migratory background in HRM and organizational strategies. The international research on DM practices towards Third Countries Nationals entailed two underlying ideas. The first -by combining classical work (e.g. Cox, 1993; Kandola and Fullerton, 1994; Thomas and Ely, 1996) and more recent research (e.g. Karataş-Özkan et al., 2014; Klarsfeld, 2012; Kumra and Manfredi, 2012) in the field-consisted in the conception of DM as an HRM approach aimed at recognizing "elements of differences" among employees (in terms of attitudes, experiences and identities) and handling workforce diversity to the benefit of the organization's goals and performance. Secondly, within this broad frame of reference, a specific focus was put on cross-cultural DM, understood here as organizational practices that attend to workplace diversity related to employees' national origin and in particular to the presence of personnel with a migratory (non EU) background.

\section{Method and Data Collected}

In order to meet the goals established above, the research was conducted in $10 \mathrm{EU}$ member states: Estonia, Finland, Germany, Hungary, Italy, the Netherlands, Poland, Portugal, Spain, and Sweden. We implemented a two-step approach. The first step was a desk research aiming at assessing how the issue of unused or misused foreigners' skills has been addressed in both research and practice.

The second step was empirical. Its central component consisted in the study of more than 100 organizations with experience in the practice of DM. A minimum of 10 organizational case histories in each of the 10 countries involved were carried out. Organizations were selected in order to guarantee in each national sample the inclusion of for-profit, public, and non-profit entities; each of these also showed commitment to the inclusion and exploitation of TCN human resources. More precisely, the final sample consisted of 104 organizations situated in the for-profit (42), public (34) and non-profit (28) spheres. A further increase in heterogeneity was obtained with respect to both size and sector variety by including small-to-medium organizations and large ones (in terms of number of employees) operating in a wide range of domains such as manufacturing, social and health services, agriculture, financial services, logistics industry, business consultancy, higher education, ICT, arts and entertainment, international cooperation. The qualitative study was based on: (a) the use of a shared thematic check-list for both fieldwork and data analysis; ${ }^{8}$ (b) the use of the same types of primary and secondary sources for data collection, which comprised, firstly, semi-structured interviews with both TCN and national employees from different hierarchical levels and organizational departments (3-6 for each case history),

\footnotetext{
${ }^{7}$ A second area addressed the issue of enhancing the recognition of migrants' knowledges, skills and competences acquired in formal, non-formal and informal contexts, with a specific focus on those gained thanks to the migratory background. A third area dealt with the challenge of "transforming" migrants - often perceived as people in need and supported by the welfare apparatus- into very proactive individuals, enhancing their role and expressing their potential in both the economic and the civil sphere, with particular emphasis on their contribution to volunteer non-profit organizations.

${ }^{8}$ The check list was structured around seven broad areas: 1) organizational history and current activity and strategies; 2) organizational demography with a particular focus on TCNs' presence and roles; 3) organizational culture and climate; 4) human resource management practices (recruitment and training processes, career and professional development, etc.); 5) emergent perceptions about socio-cultural diversity in the workplace; 6) DM actions and initiatives (in general and with particular regard to TCN human resources); 7) outcomes, impacts and criticalities of cross-cultural DM practices.
} 
and, secondly, materials provided by the selected organizations (e.g. internal reports), their websites and external documents concerning them (press articles, etc.).

Fieldwork was conducted between spring and autumn 2014, resulting in the production of 10 country reports ${ }^{9}$ that constituted the basis for the transnational analysis.

\section{Immigrant Workers and Cross-cultural DM Actions: A Multifaceted Picture from the Field}

As a result of the desk research, cross-cultural DM clearly appears as an underdeveloped, if not neglected, domain. To date, with perhaps a few exceptions (e.g. the Estonian strategy and debate about "smart migration policy" for attracting highly qualified foreign workers), attention and commitment to cross-cultural DM have been meagre, especially if compared to other target groups of DM initiatives such as women or people with disabilities. The rest of this section and the next one outline the main results produced by the empirical study on cross-cultural DM conducted in the 10 countries involved in the project.

\subsection{Reasons for Recruiting Third Country Nationals}

In most of the cases observed, cross-cultural diversity emerges as an issue hard to frame in that many organizations do not employ the concept of "TCNs" or "non-EU citizens" as a category in considering (let alone registering) the socio-demographic characteristics of their personnel. Another difficulty in dealing openly with the otherness of immigrant co-workers lies in the ambivalence that frequently came out of interviews. For example, as many interviewees resolutely stated, their organization has a "color blind" approach, meaning that their recruitment policies and workforce composition are strictly determined by competence-driven criteria. Only professional abilities are assessed, no other individual characteristics. However, this claim often appears to coexist with another conviction: TCN employees bring broader traits and styles of action at their workplace that are perceived (through various combinations of experience-based accounts and cultural clichés) as linked to their distinctive national backgrounds and as advantageous for the pursuit of organizational goals (e.g. a "natural" inclination towards adapting to tasks, becoming committed or using negotiation skills).

These organizations' recurrent self-representation as employers whose hiring practices are guided by neutral performance-oriented standards corresponds to their evolution and current situation. When delving into more detail, this picture reveals a series of reasons for resorting to immigrant workers. The most reported one is the need to fulfil specific job vacancies created by labor shortages. This particularly applies in the case of low-skilled jobs in sectors like healthcare and manufacturing (e.g. Italy), agriculture (e.g. Spain) and homecare and personal assistance (e.g. Sweden). Another relevant point is a variation on the same theme consisting in the organizational search for human resources with highly qualified skills. A striking example is Estonia, where the limited stock of nationals with specific skills drives the search for foreign talents and experts -TCNs included- to be employed in high technology fields, crucial for the country's economic development (like ICT and energy industry). This type of motivation can also be found in other countries, for instance Finland and Germany with regard to universities competing in the research and higher education markets, the Netherlands with regard to scientific departments in healthcare organizations, or Portugal with regard to "creative" professions in the domain of cultural production.

A third driver of immigrant inclusion, which at times mingles with the preceding one, is represented by the "staff global mobility" strategy as implemented by multinational companies. Foreigners with the right set of skills may move between the branches of companies spreading worldwide. This is particularly the case in the "new" EU member states (Estonia, Hungary and Poland), which, since their move towards a free market economy in the 1990s, have been increasingly penetrated by international corporations.

A fourth key reason underpinning the recruitment of immigrant employees is the search for a linguistic and cultural match between personnel and specific markets in which a similarity between staff and clients facilitates the effective delivering of services through a better understanding of the needs and expectations of the latter. Albeit also present in the for-profit sector where an international clientele is served, this motivation emerges as very significant for entities in the public and non-profit sectors that deal directly with immigrant users such as healthcare organizations interacting with local populations. Furthermore, an engagement in accomplishing this "matching mechanism" is shown by non-profit organizations whose goals are expressly in the domain of cultural diversity or involve initiatives on migration-related issues (e.g. inclusion of Russian-speaking people in Poland, promotion of Roma and refugee rights in Hungary).

A similar logic applies in the case of non-profit organizations endowed with a mission that explicitly entails the hiring of foreign

\footnotetext{
${ }^{9}$ A synthesis of the national reports is provided in the final volume (Zanfrini, 2015). Integral versions are available at: http://www.ismu.org/en/diverse-national-reports-wp-3/.
} 
workers for civic or social purposes. This is particularly well illustrated by an Italian internet communication group that hired young second-generation migrants for its editorial staff with the explicit goal of giving a voice to the "new Italians" for the benefit of all.

\subsection{The Development of Cross-culture DM Practices}

Understanding the reasons for recruiting TCNs is of utmost importance to analyze the experiences of cross-cultural DM in the observed organizations. Firstly, it helps explain immigrants' roles within these organizations. In particular, in organizations "importing" specific highly qualified competences from abroad, TCNs are both involved in core processes and offered remarkable career opportunities. This predominantly takes place in firms operating in technological fields and/or within a multinational company's network, but it may also be observed in academic organizations, with regard to teaching and research activities, and non-profit organizations with cultural diversity-related goals, in which TCNs are frequently endowed with significant responsibilities in managing projects and teams. That said, top hierarchical levels as well mid-high responsibility positions are held by national members in the vast majority of organizations. Besides constituting a considerable presence in sectors mainly characterized by low-qualification professions and vacancies, migrant workers are chiefly employed in a variety of low-skilled jobs (cleaning, catering, distribution of supplies etc.) or in operative tasks (e.g. in manufacturing).

Moreover, the reasons for recruiting TCNs shed light on the processes whereby DM has taken shape in these organizations. The first key mechanism can be traced back to a factor that, in almost all the countries involved, has been pivotal in stimulating general awareness as well as concrete initiatives about the role of diversity in the workplace: the institutional promotion and enforcement of Equal Employment Opportunity (EEO) policies, which, following EU Directives on the implementation of equal treatment principles, have assumed an influential role in all EU countries, included new Member States in their post-accession compliance efforts. This is therefore no surprise that some practices have been developed in order to comply with EEO requirements, sometimes -especially in the case of public entitiesby implementing mandatory equality measures (e.g. Finland, Hungary, Spain). It is worth noting here that organizational initiatives triggered by compliance pressures, strictly speaking, do not fall under the "umbrella" of DM, since the latter -as a voluntary organizational strategy- does not simply consist in adapting to new legal frames. Nevertheless, and although equal treatment programs among the investigated organizations have initially or predominantly addressed other diversity issues (such as, typically, gender discrimination), these policies have contributed to increasing the attention paid to inclusiveness in a broader sense.

A second mechanism at the origin of the development of DM interventions is represented, particularly in large businesses, by strategic changes involving the "caring" of foreign employees recruited specifically for their qualifications and whose contribution is deemed crucial for gaining competitiveness. This is the case of firms coping with sector-specific challenges (e.g. the energy and oil industries in Estonia and Hungary respectively) and, even more apparently, of companies pursuing international expansion. Internationalization in itself has a leading role, as for subsidiaries of multinational corporations, in which a practical focus on DM often takes shape as a reflection of a commitment taken in the parent company.

Another significant process underpinning the emergence of practical attention to cross-cultural diversity is the growing importance of Corporate Social Responsibility (CSR) programs. Unlike interventions conforming to EEO requirements, these organizational initiatives are entirely voluntary. They are variously based on both ethical grounds with the firm's role as a "corporate citizen" and business-oriented motivations like the attempt to reap reputational benefits. The role of this mechanism is portrayed in several case histories (firstly in Germany, Hungary and Poland, but also in Italy and the Netherlands) regarding organizations -especially large (internationalized) companies- for which the implementation of diversity policies represents a central line of action as well as an external indicator of their social performance.

When considering the "social significance" attached to DM conducts, we are led to identify a further relevant dynamic in their development: attention to cross-culture diversity (as to other diversity categories) chiefly arising from the ethical values entailed by the organization's mission and culture. This is clearly discernible for non-profit organizations whose goals and strategies are explicitly directed towards the promotion of cross-cultural diversity, and, more generally, for associations with a shared "cultural ethos" inherently reflecting the principle of openness to otherness.

The influence of an ethical vision can also be identified for public and for-profit organizations. For public actors, this typically emerges either through an enhanced self-awareness of their broader role in the context of an ever-changing societal context (e.g. the transformation of a German municipality's "equality office" into an "intersectional equality office"), or in connection with sector-specific features (e.g. healthcare and academic institutions with their traditional value orientations such as respect for the person and centrality of international exchanges in scholarly research). As regards businesses, in addition to formal CSR programs, an ethical driver can be seen in the development over time of socially oriented organizational cultures whose basic tenets are consistent with the moral concerns implied by diversity. This condition is quite visible in several small firms within the sample (e.g. in Italy), usually deriving from the 
influence of the founder or the entrepreneur's value-system and experience. But the role of ethical commitment, sustained by members in executive level positions, can also be grasped in some large companies. This is notably the case for a Hungarian grocery retailer and a Polish packing firm, which (well beyond workforce needs) have taken the "risk" of hiring a group of TCNs (staying in a reception center in the former instance; many unemployed women aged over 50 in the latter) with the clear intent to send a message to the surrounding socio-economic environment.

Besides involving a series of other points, ${ }^{10}$ the development of DM endeavors in the selected organizations highlights a general process that appears to underlie many of their trajectories. This consists in what can be regarded as an "evolutionary path" by which attention to diversity (and to cross-cultural diversity) has formed spontaneously, rather than strategically, from both the acquired and the on-going experience of the organization. In this respect, an organization's "natural history" affects how workplace diversity is constructed and addressed. This is suggested, for example, by the intriguing case of a Dutch university, where a physical and social separation has developed over time between research departments and the medical center that has seemingly contributed to the current gap between the former's commitment to promoting cross-cultural diversity and the latter's weak focus on it. This evolutionary dynamic may unfold as a real longitudinal learning process, through which dealing with contingent needs and pressures (e.g. to fill job vacancies) tends to be elaborated into a more reflective approach. A case in point is an Italian trade union for which the challenge posed by an unexpected increase of TCN workers in local enterprises has engendered a path of innovation entailing the placement of foreign personnel in important coordination and bargaining roles.

\section{Work in Process: Practices, Impacts and Challenges in the Recognition and Development of Immigrant Human Resources}

This section focuses on the variety of practices of immigrant promotion carried out in the studied organizations and their impacts, as well as some related implications.

There are two general observations to be made about DM policies and interventions. Firstly, such actions are not planned and implemented out of a specific focus on workers' national origin or migratory background. Rather, they are often realized on the basis of a "sensitivity" towards the importance for employees of seeing their needs and identities recognized in the workplace, and/or within a wider frame of attention often primarily involving other categories of difference. For illustrating how actions in this respect may be intertwined, let us take two cases from our sample: in order to reap benefits from diversity, a large German ICT company has developed a comprehensive DM architecture centered on four commitment dimensions that are "gender intelligence", "cross-generational intelligence", "culture \& identity" and "differently able people"; in recent years, a Hungarian Ministry has given continuity to its engagement in the implementation of several national and EU programs aimed at enabling members of specific groups (like Roma, students with disabilities and mothers with young children) to gain professional experience or even find a job in the public sector. Practices specifically targeting foreign employees can be more easily found, as expected, in companies pursuing internationalization as a human resource or market strategy, and non-profit organizations whose social ends precisely entail the employment and empowerment of immigrant personnel.

Secondly, cross-cultural DM practices are usually informal and characterized by the "evolutionary factor" alluded to earlier, notably in southern European countries (Italy, Portugal, and Spain). They did not emerged as a planned and formal system of policies, but rather as something that "is done" ('a natural, non-deliberate management of diversity', in an interviewee's words) and that is tightly connected to the unfolding experience of the organization. In this process, a key role is played by various forces such as idiosyncratic internal organizational cultures and external societal conditions or changes (like an increased supply of immigrants with acknowledged qualifications).

\subsection{Areas of Practices}

The DM practices observed in our international sample can be grouped into four broad areas.

A) Forms of practical support enabling TCN employees to tackle basic work and life issues. This type of attention, particularly evident in some national samples (e.g. Estonia, Italy, Poland, and Spain), is realized through an array of actions that concretely support immigrants in their efforts to handle a set of fundamental needs mainly related to their

\footnotetext{
${ }^{10}$ The main one is the identification of the actors with a leading role in this developmental process: first of all HR managers (in both for-profit and public organizations) and then top executives and entrepreneurs (especially in small firms without an HR department); more rarely, staff in CSR units and in teams formally devoted to diversity (whose presence can be found only in very few cases). Interestingly, in several settings - particularly but not exclusively non-profit organizations- a pivotal influence is that of single members highly committed towards DM issues, for instance employees with a distinctive professional background (e.g. in psychology or anthropology), or a personal involvement coming from direct experience as a foreign newcomer.
} 
"status" as foreign workers. Recurrent practices in this area are the following: the granting of extended leave periods and of the possibility to pray during working hours (which is very important for many Muslims); assistance in the process of family reunion; support to workers with health or financial problems; offering consultation to newcomers upon arrival (or even before arrival) about the practicalities of daily life in the host country; flexible work scheduling aimed at allowing employees lacking other kinds of support to take care of children and other family members. In several cases, these actions are performed on a quite regular basis or following established procedures; this typically takes place during insertion practices, for instance through the "welcome day" or by providing foreign newcomers with a "welcome kit" (containing information in different languages). More frequently, however, these interventions are neither planned nor formally regulated, or even implemented on a case-by-case basis. But regardless of their degree of formalization, they appear to be central for making migrant workers feel integrated in the workplace and -according to interviewees in several organizations- achieve an individual condition of serenity and involvement at work.

B) Changes and initiatives in human resource management. In certain respects, some of the above-cited actions could be seen as "technically" fitting into the domain of HRM initiatives, as in the case of flexible work arrangements (e.g. a Hungarian human rights organization where working from a home office is allowed and foreign employees, at times, perform activities from their home country) and work-life balance practices (e.g. a German energy company whose employee welfare system includes day-care centers and vacation-care service for personnel's children). More generally, what must be remarked is that forms of attention to TCN workers can be detected in the various areas constituting an organization's HRM system.

To begin with, this regards recruiting, notably where hiring is targeted to overcome difficulties in finding national applicants for a position. This may entail substantial initiatives like formal agreements with foreign partners, a mechanism recently utilized by some healthcare organizations that have hired considerable numbers of nurses on the basis of country-level bilateral programs with Third Countries (in the Netherlands) or by means of a direct agreement with an Albanian training center (in Italy). Furthermore, recruitment practices tend to intertwine with actions for the integration of newcomers, which sometimes involve buddy schemes linked to a wider coaching system in the organization.

A second crucial HRM area concerned with cross-cultural DM practices is organizational training. Here, as predictable, dedicated interventions in certain activity sectors are addressed to immigrant employees that represent key organizational resources. More than occasionally, though, significant initiatives involve also immigrant staff performing low-qualified tasks. In the latter case, training opportunities mainly play a "compensatory" role for incentivizing workers in organizational positions with limited advancement prospects; but, as suggested by several cases, this sometimes results in improving one's function and obtaining positions of some responsibility like coordinating work teams. Within the entire sample, we very rarely found the training initiative that experts in the field indicate as the most advanced when it comes to DM and cultural diversity: awareness-raising programs for all employees and HR professionals in particular. This only occurs for a Hungarian gas and oil company doing intercultural training directed towards newcomers and two large Dutch companies promoting "sensitivity training" with the aim of helping personnel to avoid selective bias in recruitment processes and work group interaction. However, some efforts in this direction emerged in the challenging sphere of "organizational development", although at an embryonic stage. An interesting case is provided by an Italian public organization in healthcare, whose recent action-research initiatives directed to map the professional characteristics of foreign employees and bring to light different views of care practices may be regarded as an early attempt at knowledge management in the diversity field.

C) The socio-cultural development of an inclusive work environment. A third main area in which DM actions are realized is the development of inclusive cultures and their communication and sharing among personnel. Such dynamics often involve the use of formal means, as the appointment of cultural mediators (e.g. in Germany, the Netherlands, and Spain) who are mostly employees with a migratory background and therefore expected, among other tasks, to act as role models for immigrant co-workers. Another formal channel consists in the adoption of organizational codes of conduct and mission statements explicitly mentioning diversity issues and goals. These sensitizing tools are often used by large and internationalized companies but may have a role in other settings too. For example, two Hungarian non-profit entities issued a "handbook" on diversity within their structure.

On the other side, a key influence in the creation of an "integrated" workplace is that of more informal social processes. Visible in many case histories, this starts from a positive relational climate based on direct communication between workers and supervisors and collaborative leadership styles (with the exception of some highly bureaucratic contexts among large public institutions). These underlying dynamics contribute to the shaping of recurrent situations of mutual exchange and recognition from which immigrant workers benefit too. Further mechanisms that render the experience of cultural diversity normally accepted relate to working practices like the use of multi-ethnic or multinational teams and holding regular meetings within organizational departments. These emerge as occasions of both dialogue and conflict 
management enhancing mutual recognition and reducing ordinary adoption of cultural stereotypes. As displayed by some national studies, processes favoring mutual recognition and appreciation may develop also through more or less organized social events. One remarkable example is the promotion of intercultural parties, usually involving employees' families, as in the case of a Spanish agricultural company where the owner promotes the organization of periodic gatherings to alleviate foreign worker's homesickness. But it is possible to identify other types of social "situations" facilitating intercultural exchanges and the strengthening of bonds of friendship between co-workers. The most emblematic case is offered by a Polish packing company, where young Nigerian women give free English lessons to their colleagues in the factory's premises, and where meetings are held after hours with the support of corporate management to discuss diversity-related issues (e.g. Islamic culture).

As suggested by the examples cited above, the formal and informal dimensions of organizational life often mingle in the formation of inclusive organizational cultures. Needless to say, the influence of this interdependence is amplified within contexts of action where goals are openly oriented towards cultural pluralism and dialogue.

D) The creation of formal programs and roles devoted to managing diversity. The role of formally planned DM initiatives -with more or less direct effects also on TCN personnel- is clearly apparent in some cases. The most ambitious expression of a systematic approach to the implementation of DM is represented by the creation of an organizational unit formally dedicated to diversity issues. This only occurs in a couple of large Dutch organizations where a diversity team performs a comprehensive array of activities ranging from counseling (to employees) and advising (to high-ranking managers), to acting as internal trainers. Other interesting examples of a more deliberate and targeted practice of cross-cultural DM include: an Italian small business whose owner and union representatives have signed an agreement specifically directed to guarantee minorities' religious rights in the workplace (e.g. having breaks for praying); and a network organization established by several Dutch providers of care with the aim of improving services for migrant users and providing opportunities to TCN professionals in this sector.

These last observations emphasize a more general point: the notable gap between the low degree of formalization of DM interventions, as observed in the organizations studied, and what "canonical" models depict or recommend as a strategic investment in DM. ${ }^{11}$ As said, formally organized mechanisms and tools only appear as exceptions. ${ }^{12}$

\subsection{Impacts of Practices}

Notwithstanding the lack of systematic impact appraisal, most of the observed organizations have developed awareness of the effects -and particularly the benefits- of their action in cross-cultural DM. As illustrated above, immigrant employees undoubtedly draw advantages from these practices. Besides the various kinds of practical support and the opportunity for professional development and advancement, they are likely to gain "symbolic" rewards such as a sense of identity and social belonging that stems from the experience of feeling engaged and being considered in the workplace. Moreover, it is possible to detect benefits for organizational personnel as a whole, in terms of both professional and personal enrichment; in the words of one interviewee, 'a multicultural environment means continuous learning'.

From another angle, it is reasonable to posit that the cross-cultural DM practices identified produce positive impacts on the socio-economic contexts involved, by contributing to local processes of social integration and -where immigrants' potential is actually exploited (e.g. through the assignment of relevant functions)- human capital development. Furthermore, these initiatives and their results frequently emerge as vehicles for sensitizing external stakeholders on diversity and inclusion issues. In this respect, we are led to think that the role of DM efforts within the social responsibility strategies of several companies lies fundamentally in their capacity to "send a message" (e.g. some Hungarian large firms engaged in Roma programs). When diversity goals as such underpin the organizational mission and "ethos", this contribution takes shape, more radically, as a function of cultural education and dissemination. Finally, it must be stressed how some organizational advantages engendered by cross-cultural DM overlap with broader societal benefits to the extent that these practices result in a response to the new needs of a changing and increasingly heterogeneous society.

\footnotetext{
${ }^{11}$ According to this literature (e.g. Kalev et al., 2006), a strategic approach to workforce diversity is primarily revealed by $a d$ hoc processes like creating a DM position or function, formal training, including diversity-related results in the assessment of executives' performance, and impact measurement.

${ }^{12}$ As already hinted at for diversity teams, it is essentially in the Dutch sample that we find these exceptions. Within it, other cases are an internationalized bank and a public healthcare organization having diversity among their KPIs (Key Performance Indicators). Although here DM goals have a minor role in the overall assessment, this practice signals that diversity matters in the organization.
} 
However, the benefits of cross-cultural DM that are suggested in greater detail by the study concern the organizations' performance. This is explicitly the case with many for-profit organizations, with respect to the advantages indicated below.

- Improvement of worker commitment, and identification with the organization and retention. The processes of integration and recognition variously entailed by DM interventions fuel the motivation of TCN employees, their commitment towards organizational tasks and goals, and their desire to remain in the company (as testified, on average, by low turnover rates). This is often the result of a supportive organizational climate, which also eases national workers' acceptance of diversity in their workplace.

- Opportunities and resources for process/product innovation and the development of alternative ways of doing things. This regards primarily organizations whose business strategies involve the recruitment of highly skilled foreign professionals, but can be seen in other situations as well. For instance, a Dutch pharmaceutical company where TCN researchers trained differently from their Dutch counterparts contribute to creating a more "holistic" scientific approach through their very meticulous way of scrutinizing data before dismissing a research route.

- Enhancement of the enterprise's reputation. For a certain number of firms, the implementation and communication of DM initiatives convey a legitimizing image among stakeholders, including business partners and clients, public institutions and employees themselves. When conducted in a social responsibility framework, DM actions allow their adopters to gain visibility in competitions held in this domain. Even more profoundly, in some contexts (e.g. Hungary, Poland) large enterprises promoting DM are perceived as "corporate citizens" playing an active role in the economic and social life of the local community.

- New marketing opportunities linked to the multicultural composition of organizational staff. A focus on cross-culture DM has led several companies in the sample to have a pool of human resources "naturally" qualified to fulfill the needs of multicultural customers. At times, this appears crucial also for international expansion strategies. An exemplary case is an Italian multinational company in the food and beverage sector, whose current aim is to use immigrants' linguistic and cultural competences for both adapting to an increasing multinational clientele in the country and penetrating new markets represented by foreign workers' countries of origin.

To a variable extent, the preceding DM-related advantages can be grasped also for non-profit and public organizations. For instance, the cultural matching mechanism is found among many healthcare organizations which, having "cultivated" TCN personnel, deal more effectively with immigrant users (e.g. Italy, the Netherlands, Sweden). Quite emblematic is the case of a large provider of mental healthcare in the Dutch sample, which, in front of immigrant groups' increasing inclination to look for psychological support, sees people with a migratory background as a promising new "market". Another case in point is that of some non-profit entities successfully managing projects abroad through collaborators with in-depth knowledge of the social, political and legal aspects of the targeted regions.

As for the development of a positive reputation among primary stakeholders, in several cases this has resulted in enhanced ability to attract talented candidates (e.g. academic institutions) and, sometimes, external funding. By the same token, particularly within the scientific and cultural sectors, improvements in problem-solving and innovation can derive from the variety of ways of thinking fuelled by an increased internal diversity. But the most radical illustration of the positive impact of DM practices is offered by (mainly non-profit) organizations where the multicultural staff composition is regarded as key to "have the job done". This is perfectly exemplified by the already-mentioned Italian organization in the field of communication whose mission of stimulating debates on the development of a "diverse" national society is achieved by using an editorial staff made up entirely of "new citizens" who simultaneously live in two worlds.

In a nutshell, many of the case histories are in line with the concept of "business case for diversity", according to which diversity in the workplace and its management are pivotal for improving organizational functioning and capacity of value creation.

\subsection{Facilitating and Constraining Factors}

Within this landscape, the study has also highlighted a number of facilitating factors in the implementation of cross-cultural DM actions. On the one hand, these are given by contextual conditions, and in particular opportunities provided by the institutional environment (e.g. easier procedures for hiring TCNs, as in the Netherlands and Spain) and influences connected to the organization's sector of activity (e.g. high degree of openness to innovation, opportunities for direct and continuous interaction with clients, using English as the common language for daily operations). In this regard, as suggested by our results, organizations in the non-profit sector may have some sort of intrinsic potential for the development of DM practices; that is, a set of resources for the enhancement of cross-cultural diversity (and other types of differences) that are "carved" into their organizational forms, cultures and ends. This is illustrated by an Italian social cooperative where attention to internal diversity has developed also thanks to the expertise gained by dealing with 
heterogeneous users in the field of social exclusion.

On the other hand, favoring and sustaining the implementation of cross-cultural DM practices require at least three conditions at the organizational level. These are: the personal involvement and sponsorship of high-level managers; a broader attention to, or previous experience with, other differences in the workforce; and the presence of a socially oriented or "ethical" culture underpinning the organization, especially when it is fed by internal processes of sharing-of-meaning.

That said, it is not all a "bed of roses". The study has also shed light on a set of constraints and criticalities in the practice of cross-cultural DM which, again, can be related to both situational and internal factors. In the case of situational factors, the chief problem lies in increasing budget cuts that may result in the temporary suspension, if not dismissal, of the initiatives launched. Pressure to reduce costs, amplified by the recent economic crisis, is reported for public and non-profit healthcare organizations (e.g. Germany, Italy, the Netherlands, and Sweden), but occasionally involves businesses as well. As for internal factors, several critical points have emerged which can be traced back to the lack of a coherent framework for DM interventions. Such criticalities are mainly linked to organizational size (e.g. for small organizations, barriers to dedicating financial and human resources) and complexity (e.g. difficulty in circulating practices within networks with semi-autonomous components), time pressures and weak determination in passing from statements to implementation. Another problem consists in perceived reverse discrimination, which occurs when national workers fuel the idea that foreigners are recruited because of their "otherness" and minority status rather than their skills.

Also, DM actions are sometimes rendered difficult by TCNs' limited knowledge of the local language and differences in cultural background and experience. For instance, this happens in the healthcare sector when immigrant nurses and doctors come from medical systems in which the former have less responsibilities and the latter perform more tasks (e.g. the Netherlands, Sweden).

In conclusion, it is plausible to argue that, in the observed contexts, the "machine" is on the move on the front of cross-cultural DM. But, in light of what comes out from the international study, three challenges seem to be currently pivotal for the promotion of these practices in organizations as well as for further research in the field. Firstly, there is a necessity to openly address the possible -perhaps, inherent- ambivalence of a focus on diversity valorization when this is pursued in organizational and social contexts emphasizing the logic of equality. A second challenge regards the need to develop a deliberate and more strategic frame of reference for managing workplace diversity while avoiding the risk of top-down "engineering" disconnected from the experience of diversity as felt by the workers concerned ('something not linked to the natural flow of things', in one respondent's words). Finally, a more general point that must be carefully considered is that the success of DM actions depends heavily on what falls outside the sphere of organizational efforts and control, involving other actors and other policies for the integration and exploitation of TCNs' human capital.

\section{Discussion and Conclusion}

The research presented in this article confirms how diversity has been an unexpected and unwelcome phenomenon; i.e., a reality generated by a concrete development of migrants' arrivals and settlements that has not been in line with what was officially established by migratory policies (that is, the presumption of a temporary stay strictly functional to fill a given job vacancy). This largely explains why, for most of the studied organizations, the recruitment of migrants has been neither planned nor welcome in relation to their specific skills or abilities, but resulted from the changed composition of the labor offer, particularly in the case of low-status jobs. Moreover, given the strict relationship of all this with the process of definition of the geographical and political borders of the nation-State (Sayad, 1999), each country has produced its own "type" of diversity. A "diversity of Diversities" has emerged as one of the most suggestive outcomes of our research: an output of the distinctive nation-building process and the peculiar migratory history of each country, as well as of the contemporary political scenario placing particular emphasis on specific issues. This point was recurrently revealed by our respondents, starting from their immediate reaction when asked about diversity related to immigrants' presence in the workplace. The meaning they attached to the concept of "diversity" itself, their predisposition to discuss it or "exorcize" it, the attention paid to specific ethnic and social minorities, the constraints and duties deriving from a normative frame such as that imposing a blind approach, are examples of this form of organizational embeddedness. Therefore, an important insight the research brought about is the need to tackle this issue with a certain level of awareness.

In the German case, the acknowledgment of the multi-ethnic composition of the country has been a very recent step, changing the traditional approach founded on the assumption of a (mono)ethnic national identity. In contrast, countries like Sweden or the Netherlands are today strongly challenged by nationalist arguments, to the point of questioning their traditional openness and tolerance towards diversity and the associated positive rhetoric. Italy, as the most exemplary case of a "new" immigration country in Southern Europe, has needed many years to adjust to this change of role which 
has transformed a traditional emigration area into one of the most important and attractive immigration poles in the contemporary international landscape. The tremendous growth in the number of migrants living in its territory is commonly understood as the demonstration of the government's failure to control migration, and not of the attractiveness of its economy; at the same time, the logic of complementarity -in a country traditionally affected by high rates of unemployment- has gained the status of indisputable assumption. A country with a colonial past, such as Portugal, has produced a relationship with migrants and "diversity" largely shaped by the distinction between Lusophone (people from Portuguese-speaking countries) and non-Lusophone migrants. Finally, within the former Eastern bloc countries, the reshaping of the "national" borders following the implosion of the Soviet empire has produced a substantial divergence between the official definition of foreigners - which includes those who lost their citizenship- and the self-perception of the people involved. Estonia is a case in point. Furthermore, workers coming from abroad, destined to replace highly educated native workers who emigrated, tend not to perceive themselves as migrants -or diverse- but as the members of a cosmopolitan class engaged in promising international careers. As it happens also in Hungary, their working conditions and salary are often better than those of native workers, thus introducing a diverse idea of diversity in the EU social framework.

Within this very heterogeneous landscape, the distinction between EU and non-EU migrants has turned out to be as fundamental as problematic. On one side, it represents the most striking discrimination produced by the systems of civic stratification which regulate migrants' access to rights and opportunities; on the other side, it is constantly challenged or even neglected by empirical social processes. Employers and other prominent actors sometimes refuse to adopt this distinction because it is considered incoherent with the principles of equality and meritocracy. In other cases, all people with a foreign (or non-EU) heritage -or a "foreign" phenotype- are considered "foreigners", regardless of their "real" nationality and citizenship. Finally, perceptions of, and labels on, a person's nationality and ethnic identity do not always go in accordance with official papers. Moreover, the need to resort to this categorization may even artificially erect barriers and shape practices. A case in point is represented by the rules preventing public institutions from hiring non-EU personnel, thus excluding such influential actors from the possibility to play a role in the diffusion of DM policies and practices. In more general terms, not only does this distinction involve different rules for the recruitment of TCNs -sometimes conflicting with the antidiscrimination principles themselves-, but it also reinforces the logic of complementarity, which is intrinsically discriminatory and inhibiting the process of migrant empowerment.

This unresolved contradiction largely explains many of the ambivalences that emerged from the study, starting from the one characterizing the attitude towards TCNs. Particularly in highly ethnicized sectors, as described in the previous sections, the "attention" devoted to this category of workers can paradoxically feed stereotypes linked to their ethnic and national background, contributing to the reproduction of the recruitment logics that have provoked labor market (and sometimes also organizational) segmentation. Accordingly, it often happens that TCNs' main "talent" is their availability to perform jobs that native workers do not want to do. These phenomena are really illustrative of the need for a straight, and finally explicit, reflection about the types of "diversity", values and conceptions of the (common) good we intend to enact and to link together through diversity-oriented rhetoric and practices (Zanfrini and Monaci, 2014). Both institutions and civil society actors, including the business sector, are therefore challenged by a clear ethical issue, related to the kind of "diversity" we need to acknowledge, protect and exploit. All this must entail attention to the risk of reifying the borders that separate different groups of people and workers (for example, the border between natives and migrants), since channeling individuals into specific categories may not mirror their real identities, expectations and talents. Indeed, this helps understand why, as suggested by the review of literature, the issue of diversity linked to TCNs' presence in organizational settings is substantially marginal, regardless of the variety of institutional milieus in which HRM practices are embedded. Firstly, in those national contexts traditionally characterized by an emphasis on rights equality and dignity, the priority decidedly goes to policies aimed at guaranteeing equal opportunities and treatment, thus discouraging any initiative aimed at acknowledging and exploiting the diversities represented in personnel. Moreover, where an institutional context stressing meritocratic principles prevails, any discourse about diversity tends to be exorcized as it would immediately evoke the risk of prejudice and differential treatment. In this perspective, the alleged universalism can result in the expectation of homologation. Insisting on the fact that what is important is to choose the best among all applicants, the most suitable for the vacant position, HR managers neglect the role of individual characteristics that are beyond the formal job description, despite the emphasis sometimes given to them in managerial rhetoric. Ultimately, considering any form of discrimination including positive discrimination- as unlawful, can discourage the implementation of DM policies.

Finally, there are very few exceptions among those countries competing for foreign talents, but those exceptions confirm the rule, as the saying goes. According to the political and ideological framework described in the second section, the common expectation towards migrant workers regards their adaptability to low-status jobs, generally marginal in the policies for human capital development and for enhancing corporate reputation. Despite growing 
awareness of the structural character of migrations and of the "irredeemable" heterogeneous composition of EU population (Alba and Foner, 2015), this approach continues to shape policies and practices, at both political and organizational level, constraining the possibility to fully reap the benefits of the "Diversity Value".

All this explains both the scarcity and the ambivalence of DM initiatives and their content, starting from their significant focus on practical support related to TCNs' basic needs, as illustrated above. Even more intriguing is how, in various cases, DM practices identified by the study find their rationale in the need to manage difficulties and conflicting situations, largely due to the tendency to consider migrants as "outsiders" to a community made of long-term residents belonging to a nation defined as a common heritage. Given this landscape, our study contributes to casting light on a series of potentially promising experiences, even though they often lack visibility. This research has actually allowed the identification of a multiplicity of initiatives and programs, often emerging in a spontaneous and unplanned manner. We have defined them in terms of an "evolutionary dynamic" in the practice of diversity, which is often neither formalized nor displayed through assessment and communication strategies. What must be stressed is that many such initiatives and programs are not classifiable according to the standards and evaluation methods recommended in management books. Consequently, another important insight offered by our empirical research is the convenience of developing new methodologies and repertoires of practices, mirroring the variety of socio-economic and cultural milieus and able to capture practices that are the outcome of an evolutionary approach. Aside from formal roles and plans for recruiting and managing a "diverse" staff, which are coherent with what is suggested by the current literature but visible in few cases within our sample-, the study allows us to identify other types of practices normally not delved into or emphasized. For example, this happens through the development of an inclusive work environment linked to the influence of informal mechanisms and emerging social processes, such as participative leadership styles facilitating mutual exchange and the formation of socially oriented value systems. More broadly, a first step in throwing light on these uncodified practices is offered by the empirically based classification proposed in the previous sections concerning practices, impacts, and some challenging implications.

Finally, as already stressed, the impact of DM practices depends on what happens outside the organization, on broader attitudes in the societal context towards migrants and their role, as well as on encouraging or hampering factors related to institutional initiatives. But, at the same time, organizations' behavior can shape the context and its cultural orientations. In the contemporary European social milieu, businesses and other types of organizations play a crucial, but maybe undervalued, role. As a matter of fact, within our international and variegated sample, we found several organizations that, more or less deliberately, follow this path. By promoting and implementing DM practices, without any obligation to do so, they are contributing to a new scenario, which could even question the most ethnocentric traditions and the migratory regimes founded on the complementarity principle. Through the appreciation and the exploitation of their migrant personnel's diversity, they may play a real political role such as: enhancing social solidarity; encouraging a deeper change of attitude towards this kind of diversity; promoting a different conception of the membership to the nation; and contributing to fueling the political debate on these crucial issues. By becoming more and more inclusive towards this type of diversity -or, better, to the "diversity of Diversities" related to the migratory background-, organizations not only strengthen their social responsibility initiatives, but also decidedly develop a real corporate citizenship strategy. Finally, they contribute -with more or less awareness- to "reinventing" the European approach to immigration. This involves transforming Europe into not only a multicultural society but also a genuine intercultural society, as well as the emergence of a new idea of belonging; that is, a sense of belonging not based on an ethnic and national common heritage but rather on individual agency, the desire to feel included, and a shared effort to improve economic competitiveness and social cohesion, taking advantage from the Diversity Value.

\section{References}

Alba, R., \& Foner, N. (2015). Strangers No more. Immigration and Challenges of Integration in North America and Western Europe. Princeton and Oxford: Princeton University Press. https://doi.org/10.1515/9781400865901

Carrera, S., Blockmans, S., Gros, D., \& Guild, E. (2015). The EU's Response to the Refugee Crisis: Taking Stock and Setting Policy Priorities. Brussels: Centre for European Policy Studies.

Castles, S. (1986). The guest-worker in Western Europe - An obituary. International Migration Review, 20(4), 761-778. https://doi.org/10.2307/2545735

Castles, S., \& Miller, M.J. (2012). The Age of Migration. International Population Movements in the Modern World. London: MacMillan.

Cox, T. Jr. (1993). Cultural Diversity in Organizations: Theory, Research and Practice. San Francisco: Berrett-Koehler.

Crul, M., \& Mollenkof, J. (2012). The Changing Face of World Cities. Young Adult Children of Immigrants in Europe and the United States. New York: Russell Sage Foundation.

Delanty, G. (2006). Immigrazione e cittadinanza europea. ISPI-Policy Brief, December, 47. 
Hammar, T. (1989). State, nation and dual citizenship. In: Brubaker, R. (ed.) Immigration and the Politics of Citizenship in Europe and North America. New York: University Press of America, 81-95.

Huddlestone, T., \& Dag, T. J. (2012). Immigrant Citizens Survey. Brussels: King Badouin Foundation.

Jamal, M. A. (2015). The "tiering" of citizenship and residency and the "hierarchization" of migrant communities: The United Arab Emirates in historical context. International Migration Review, 49(3), 601-632. https://doi.org/10.1111/imre.12132

Kalev, A., Dobbin, F., \& Kelly, E. (2006). Best practices or best guesses? Assessing the efficacy of corporate affirmative action and diversity practices. American Sociological Review, 71, 589-617. https://doi.org/10.1177/000312240607100404

Kandola, R., \& Fullerton, J. (1994). Managing the Mosaic: Diversity in Action. London: Institute of Personnel and Development.

Karataş-Özkan, M., Nicolopoulou, K., \& Özbilgin, M. F. (eds) (2014). Corporate Social Responsibility and Human Resource Management: A Diversity Perspective. Cheltenham: Elgar.

King, R., Lazaridis, G., \& Tsardanidis, C. (2000). Eldorado or Fortress? Migration in Southern Europe. Houndmills \& New York: Macmillan Press \& St. Martin's Press. https://doi.org/10.1057/97803333982525

Klarsfeld, A. (2012). International Handbook on Diversity Management at Work. Cheltenham: Elgar.

Kumra, S., \& Manfredi, S. (2012). Managing Equality and Diversity: Theory and Practice. Oxford: Oxford University Press.

Miège, J. L. (1993). Migration and decolonization. European Review, 1, 81-86. https://doi.org/10.1017/S1062798700000417

OECD (2014). European Union, Matching Economic Migration with Labour Market Needs, Paris: OECD Publishing.

OECD (2015). International Migration Outlook. Annual Report, Paris: OECD Publishing. https://doi.org/10.1787/migr_outlook-2015-en

OECD \& EU (2016). Recruiting Migrant Workers: Europe 2016. Paris: OECD Publishing. https://doi.org/10.1787/9789264257290-en

Okólski, M. (ed.) (2012). European Immigrations: Trends, Structures and Policy Implications. Amsterdam: Amsterdam University Press.

Papademetriou, D. G., \& Hamilton, K. A. (1995). Managing Uncertainty: Regulating Immigration Flows in Advanced Industrial Countries. Washington DC: International Migration Policy Program-Carnegie Endowment for International Peace.

Sayad, A. (1999). Immigration et 'pensée d'Etat'. Actes de la recherche en sciences sociales, 129, 5-14. https://doi.org/10.3406/arss.1999.3299

Thomas, D. A., \& Ely, R. J. (1996). Making differences matter: A new paradigm for managing diversity. Harvard Business Review 74 (September-October), 79-90.

Triandafyllidou, A., \& Vogel, D. (2010). Irregular Migration in Europe: Myths and Realities. London: Ashgate.

Valtolina, G. G. (ed.) (2013). Migrant Children in Europe. Amsterdam: IOS Press.

Wimmer, A., \& Glick, S. N. (2003). Methodological nationalism, the social sciences, and the study of migration: An essay in historical epistemology. International Migration Review, 37(3), 576-610. https://doi.org/10.1111/j.1747-7379.2003.tb00151.x

Zanfrini, L. (2010). I “confini” della cittadinanza: perché l'immigrazione disturba, Sociologia del Lavoro, 117, 40-56. https://doi.org/10.3280/SL2010-117004

Zanfrini, L. (2012). Family migration: Fulfilling the gap between law and social processes, Societies, 2. https://doi.org/10.3390/soc2030063

Zanfrini, L. (ed.) (2015). The Diversity Value. How to Reinvent the European Approach to Immigration. Maidenhead, UK: McGraw-Hill Education (freely accessible at http://www.ateneonline.it/zanfrini).

Zanfrini, L., \& Monaci, M. (2014). Introduzione. Di quale "diversità" e di quale "valore" parliamo? Sociologia del Lavoro, 134, 7-39. https//doi.org/10.3280/SL2014-134001

\section{Copyrights}

Copyright for this article is retained by the author(s), with first publication rights granted to the journal.

This is an open-access article distributed under the terms and conditions of the Creative Commons Attribution license which permits unrestricted use, distribution, and reproduction in any medium, provided the original work is properly cited. 